\title{
Cost-effectiveness analysis of phenotypic-guided vs. guidelines-guided bronchodilator therapy in viral bronchiolitis
}

\author{
Carlos Rodriguez-Martinez ${ }^{1}$, Gustavo Nino ${ }^{2}$, Jose Castro-Rodriguez ${ }^{3}$, Geovanny F. Perez ${ }^{4}$, \\ Monica Sossa-Briceño ${ }^{5}$, and jefferson buendia $^{6}$ \\ ${ }^{1}$ School of Medicine, Universidad El Bosque \\ ${ }^{2}$ Pennsylvania State University / Penn State Children's Hospital \\ ${ }^{3}$ Pontificia Universidad Catolica de Chile \\ ${ }^{4}$ The George Washington University \\ ${ }^{5}$ Universidad Nacional de Colombia \\ ${ }^{6}$ University of Antioquia
}

July 30, 2020

\begin{abstract}
Objectives. Although recent evidence suggests that management of viral bronchiolitis requires something other than guidelinesguided therapy, there is a lack of evidence supporting the economic benefits of phenotypic-guided bronchodilator therapy for treating this disease. The aim of the present study was to compare the cost-effectiveness of phenotypic-guided versus guidelinesguided bronchodilator therapy in infants with viral bronchiolitis. Methods: A decision-analysis model was developed in order to compare the cost-effectiveness of phenotypic-guided versus guidelines-guided bronchodilator therapy in infants with viral bronchiolitis. The effectiveness parameters and costs of the model were obtained from electronic medical records. The main outcome was avoidance of hospital admission after initial care in the ED. Results: Compared to guidelines-guided strategy, treating patients with viral bronchiolitis with the phenotypic-guided bronchodilator therapy strategy was associated with lower total costs (US $\$ 250.99$ vs US $\$ 263.46$ average cost per patient) and a higher probability of avoidance of hospital admission (0.7902 vs 0.7638 ), thus leading to dominance. Results were robust to deterministic and probabilistic sensitivity analyses. Conclusions: Compared to guidelines-guided strategy, treating infants with viral bronchiolitis using the phenotypic-guided bronchodilator therapy strategy is a more cost-effective strategy, because it involves a lower probability of hospital admission at lower total treatment costs.
\end{abstract}

\section{Hosted file}

Main Document.doc available at https://authorea.com/users/321539/articles/473221-costeffectiveness-analysis-of-phenotypic-guided-vs-guidelines-guided-bronchodilator-therapyin-viral-bronchiolitis

\section{Hosted file}

Table 1.doc available at https://authorea.com/users/321539/articles/473221-costeffectiveness-analysis-of-phenotypic-guided-vs-guidelines-guided-bronchodilator-therapyin-viral-bronchiolitis

\section{Hosted file}

Table 2.doc available at https://authorea.com/users/321539/articles/473221-costeffectiveness-analysis-of-phenotypic-guided-vs-guidelines-guided-bronchodilator-therapy- 
in-viral-bronchiolitis

\section{Hosted file}

Table 3.doc available at https://authorea.com/users/321539/articles/473221-costeffectiveness-analysis-of-phenotypic-guided-vs-guidelines-guided-bronchodilator-therapyin-viral-bronchiolitis

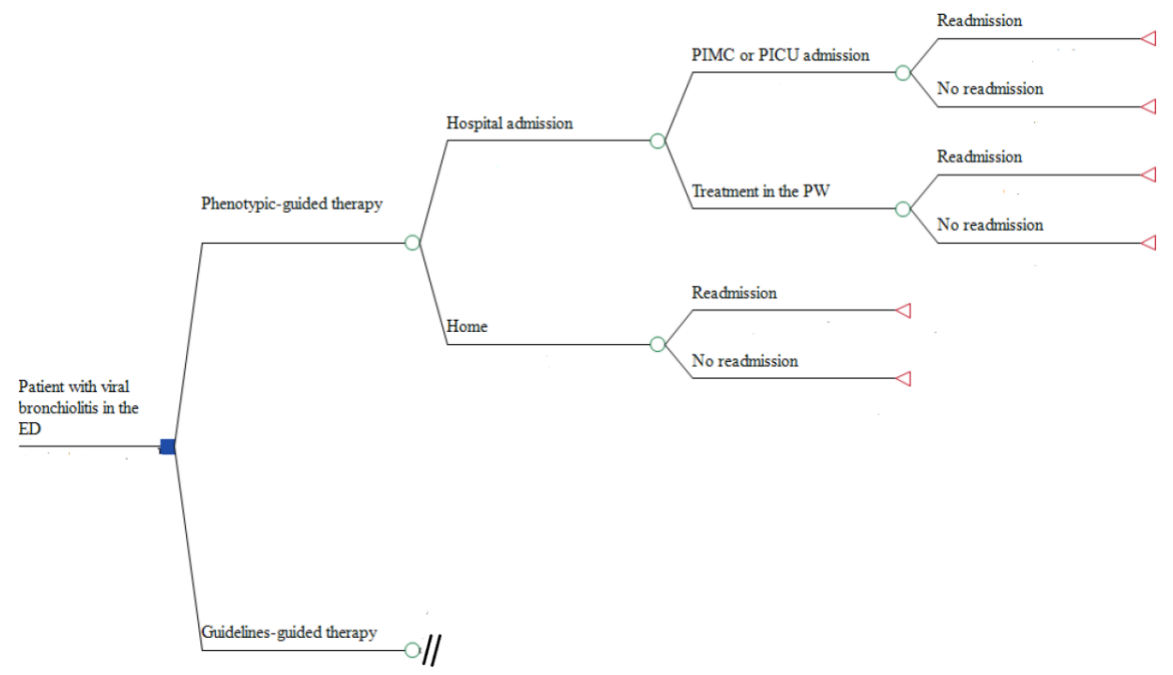

Cost-Effectiveness Scatterplot

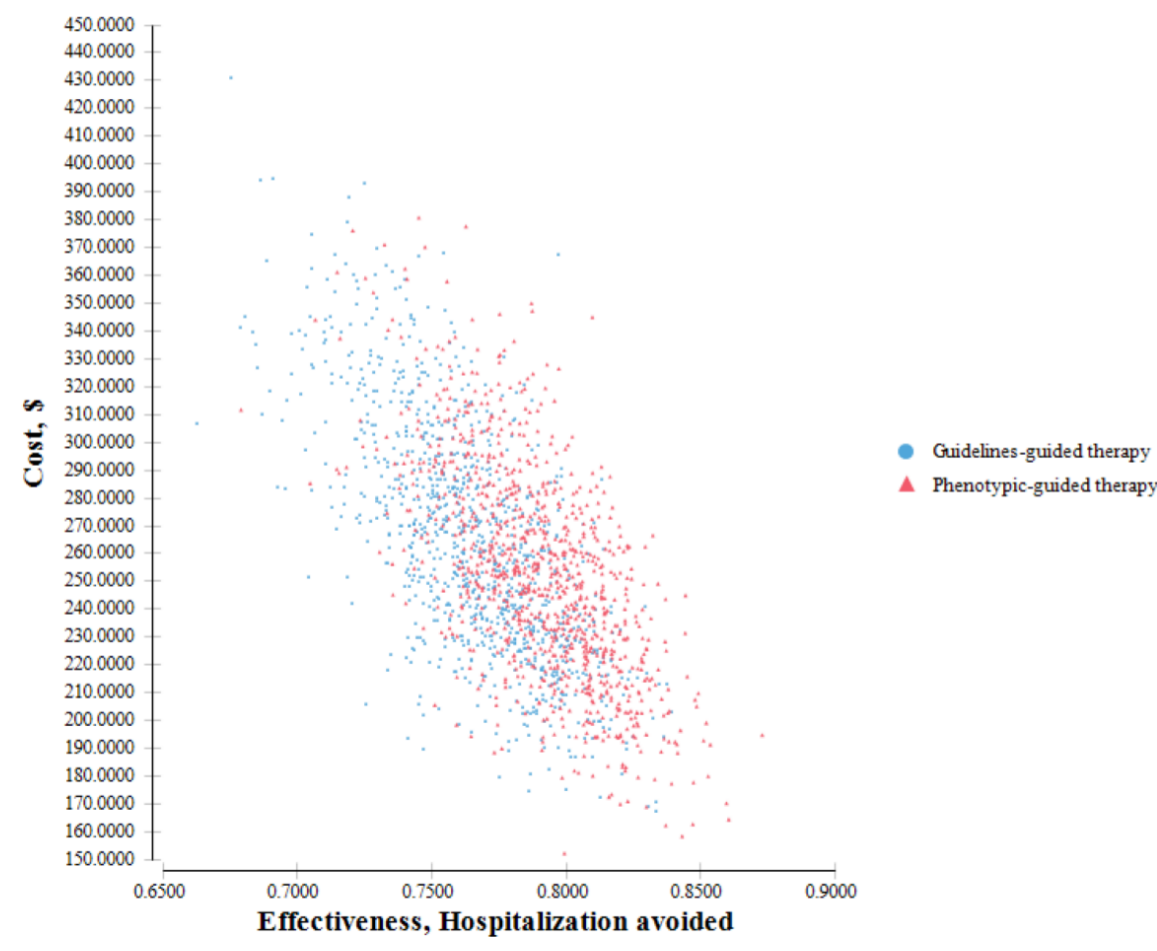

